\title{
New vitality of ancient ethnomedicine in China: Review of Li ethnomedicine
}

\author{
Yuanyuan Yu, Hao Hu, Meiwan Chen* and Yitao Wang \\ State Key Laboratory of Quality Research in Chinese Medicine, Institute of Chinese Medical Sciences, University of \\ Macau, 999078, China.
}

Accepted 20 May, 2013

\begin{abstract}
Nowadays, with the development of nature drug, herbal medicine is gaining more attention from scientists in various countries. In China, ancient ethnomedicine based on natural medicinal plants faces new opportunities and challenges. This paper examines Li ethnomedicine, which has not attracted much attention among researchers yet. Four special species, which had important significance for modern research and were very helpful for treating modern diseases, such as cancer, cardiovascular, and cerebrovascular disease, were selected for a concrete analysis from the perspective of function, economic value, developmental potential, and industrial base in order to introduce the $\mathrm{Li}$ ethnomedicine to the world. The development status and main problems of $\mathrm{Li}$ ethnomedicine were summarized and discussed for further study.
\end{abstract}

Key words: Li ethnomedicine, function, economic value.

\section{INTRODUCTION}

Natural medicine appeared with the existence of human society. Before the eighteenth century, it provided the main therapeutic agents for human diseases. With the rapid development of modern medicine and the chemical pharmaceutical industry in the nineteenth century, natural medicine gradually fell by the wayside, especially in the west. In fact, the active ingredients of natural medicine or retrofitting its structure to get new chemicals have always been one of the most important sources of chemical medicine. In recent years, developed countries had shifted their research focus to the natural medicinal plants, indicating that herbal medicine is gaining more and more attention among scientists from various countries. This shift also brings new opportunities and challenges to the exploitation and development of ancient medicinal herbs in China. This paper examines $\mathrm{Li}$ ethnomedicine and a few special species were selected for deeper study. The development status and main problems of $\mathrm{Li}$ ethnomedicine are summarized and discussed for further study.

\section{OVERVIEW OF LI ETHNOMEDICINE}

\section{Representative plants of Li ethnomedicine}

The Li people have lived in Hainan for more than 3,000 years and were the earliest ancestors to live on the island. As a minority population with more than 100 million people (Haofu and Wenli, 2008), the Li people have struggled with diseases for thousands of years and formed a unique set of medical theories and clinical experience using local herbs with significant regional and national characteristics, that are very different from the traditional Chinese medicine (Bingchun et al., 2007).

Most of the Li population on Hainan traditionally lived in mountainous area, which is rich in flora and fauna, with poisonous insects and snake everywhere and terrible traffic conditions (Junqing et al., 2009). As a result, the $\mathrm{Li}$ drugs have obvious geographical features. The $\mathrm{Li}$ pharmacy introduction (Mingsheng, 2008), includes 128 kinds of Li drugs; one sixth of them are for the treatment 
of bone injury, such as Gendarussa vulgaris Nees (Weijing et al., 2011) and Croton crassifolius Geiseler (Xianhui, 2009); while one tenth are for hepatitis, such as Eudia lepta (Spreng.) Merr (Changyu et al., 2012) and Abrus mollis Hance (Xiaobai et al., 2010). In addition, 8 are used to treat snakebites (e.g. Ervatamia hainanensis Tsiang (Xingqi, 2003)); 8 are used for cirrhosis ascites (e.g. Brucea javanica (Linn.) Merr. (Haifeng et al., 2012)); 7 for infertility (e.g. Cyrtomium fortunei J. Sm. (Junqing, 2009); 6 are used for nephropathy (e.g. Drynaria fortunei (Kunze) J. Smith. (Long et al., 2005)); 4 are used for inflammation (e.g. Ficus pumila L.) (Junqing et al., 2009). The drugs are administered externally, orally, through fumigation and by carring them (A kind of way to carry some particular drugs with small bag).

Recent studies have found that, besides the remarkable effect in the treatment of snakebites and bruises, $\mathrm{Li}$ drugs also have very significant effects as antiinflammation and anti-tumor drugs, especially leukemia, and may provide a new therapeutic approach for cancer, hepatitis, rheumatism, and other illnesses (Caicheng, 2007).

\section{Historical records}

The Li nationality has no words of its own, which means it is difficult to record the concrete history and development exhibition of its medicine. But it can be traced from some monographs of Traditional Chinese Medicine. "An Account of the Plants and Trees of Southern China", written by Ji Han (Jin Dynasty, 265-420 AD), is the earliest botany literature in China. The book reproduces several species such as Aquilaria sinensis (Lour.) Gilg, Dalbergia odorifera T.C. Chen, Alpinia oxyphylla Miq., Areca cathecu Linn, Cocos nucifera Linn, Saccharum officenarum $\mathrm{L}$. and many others. These varieties are produced in Hainan and have the same utilization with $\mathrm{Li}$ ethnomedicine.

"Findings in Lingnan Area", written by Liu Xun (Tang Dynasty, 618-907 AD), described the precious animals and plants in Lingnan area. In this book, some plants used by Li people as medicine are mentioned, such as dendrobe, olives, hawksbill. In 1950s, the Li ethnomedicine attracted the attention of Chinese government. The data of $\mathrm{Li}$ pharmacology were gathered and arranged. "Survey of Li nation in Hainan" was published in 1954, which documented the $\mathrm{Li}$ ethnomedicine specifically for the first time (Caicheng, 2007). The book "200 kinds of Chinese Herbal Medicine in Hainan" edited on the base of investigation in Hainan summed up 200 kinds of Chinese herbal medicinal materials which are used frequently by people. "Dictionary of Li nation in China" (Yingbo et al., 1994) recorded about 70 kinds of Li drugs.

Recently, two specialized books of Li ethnomedicine, "Li pharmacy Introduction" and "Records of Li Folk Medicine" were edited in 2008 , which summarized more than 100 kinds of Li drugs including the ingredient, usage, dosage, and treatment (Mlngsheng, 2008; Haofu, 2008). Nowadays, the government of Hainan is paying more attention to the development of $\mathrm{Li}$ ethnomedicine. They have made many efforts in terms of the protection, mass production, and innovation in order to help this ancient ethnomedicine regain its vital activity.

According to this review of $\mathrm{Li}$ ethnomedicine and the concrete analysis of special medicinal plants as follows, we can see that although $\mathrm{Li}$ ethnomedicine is ancient, with a history dating back 3,000 years, it still has important significance for modern research. It is very helpful for treating modern diseases, such as cancer, cardiovascular, and cerebrovascular disease (Caicheng, 2007). Some of these medicinal plants are good for people's health and can be eaten daily.

\section{FOUR SPECIAL MEDICINAL PLANTS}

This paper selects 4 species from 128 Li medicinal plants for deeper research: Callicarpa nudiflora Hook. \& Arn., Nauclea officinalis, $A$. oxyphylla, and Dracaena angustifolia Roxb. These four species have the common feature of high added value and economic value, as well as great exploition potential; they are also already used in drug production. In addition, although some are used in traditional Chinese medicine, they are used in different ways for the treatment of diseases in $\mathrm{Li}$ ethnomedicine (Table 1).

\section{C. nudiflora (Luohuazizhu)}

C. nudiflora, whose leaves can be used as medicine, is harvested in the summer and autumn and can be dried into powder from the plains to hills, valleys, streams and forests or bushes at an altitude of $1200 \mathrm{~m}$ located in Hainan, Guangdong, Guangxi. Wuzhishan in Hainan is the most appropriate place for growing it as it has the highest medicinal value. The $C$. nudiflora has an acerbic taste that is slightly spicy and bitter. Li people use it as anti-bacterial, anti-inflammatory, and hemostatic. As early as the Qin and Han dynasties, the Li people pounded the roots and leaves of $C$. nudiflora for external use on wounds or boiled them for oral administration to treat several diseases. The Li people regard $C$. nudiflora as precious and have used it for many generations.

In modern times, the $C$. nudiflora is used as an essential herb for healing by military soldiers in China. It is found that the $C$. nudiflora is very helpful for some modern diseases such as thrombus (Ying and Guocai, 2006), and can delay the process of decrepitude (Bin et al., 1995). Today, the market demand for this medicinal material is about 3,500 tons every year, with an average price of 2,500 yuan per ton and it is estimated that the demand will increase to 5,000 tons within two years, 
Table 1. Comparison of four medicinal plants of Li ethnomedicine

\begin{tabular}{|c|c|c|c|c|}
\hline Name & Callicarpa nudiflora & Nauclea officinalis & Alpinia oxyphylla & Dracaena angustifolia \\
\hline $\begin{array}{l}\text { Pharmacological } \\
\text { property }\end{array}$ & $\begin{array}{l}\text { Antithrombotic (Ying and Guocai et al., } \\
\text { 2007), anti-inflammatory (Ying and } \\
\text { Guocai et al., 2006), anti-aging (Bin et al., } \\
\text { 1995). }\end{array}$ & $\begin{array}{l}\text { anti-inflammatory, acesodyne (Liang et } \\
\text { al., 2011), lower blood pressure (Jian } \\
\text { et al., 2002), anti-virus. }\end{array}$ & $\begin{array}{l}\text { anti-dementia (Dehuan et al., 2002; Hongmei et } \\
\text { al., 2012), anti-diarrhea (Xinghua et al., 2009), } \\
\text { anti-aging (Huiling et al., 2006), } \\
\text { neuroprotective effect (Shui et al., 2006) }\end{array}$ & $\begin{array}{l}\text { Anti-inflammatory analgesic (Yuli et } \\
\text { al., 2010), anti-thrombosis (Nian et } \\
\text { al., 2010), stop bleeding, anti-tumor } \\
\text { (Wenli et al., 2005) }\end{array}$ \\
\hline Clinical use & $\begin{array}{l}\text { Bleeding(Jie et al., 2010), infectious } \\
\text { diseases (such as respiratory tract } \\
\text { infections), viral hepatitis (Jinping et al., } \\
\text { 2012) }\end{array}$ & $\begin{array}{l}\text { Acute tonsillitis, acute pharyngitis, } \\
\text { acute conjunctivitis and upper } \\
\text { respiratory tract infection, diabetes }\end{array}$ & $\begin{array}{l}\text { Hyperactivity, insomnia, Older night urine, } \\
\text { urinary frequency, sexual dysfunction, amnesia }\end{array}$ & $\begin{array}{l}\text { Bruises, chronic hepatitis, whooping } \\
\text { cough, bronchitis, tuberculosis, } \\
\text { chronic tonsillitis, pharyngitis }\end{array}$ \\
\hline $\begin{array}{l}\text { Application in } \mathrm{Li} \\
\text { ethnomedicine }\end{array}$ & leaves, fruits: stop the bleeding & anti-inflammatory & fruit (dry milling): stop stomach pain & resin: throat dry pain \\
\hline $\begin{array}{l}\text { Li ethnomedicine } \\
\text { production }\end{array}$ & Tablet, capsule, Suppository. & $\begin{array}{l}\text { Injection, extract capsule, extract } \\
\text { tablets(Yan and Yanli et al., 2012), } \\
\text { wine. }\end{array}$ & Soft capsule, wine. & Powdered medicine, capsule. \\
\hline $\begin{array}{l}\text { Economical } \\
\text { efficiency }\end{array}$ & Huge market demand & Low cost, high market demand & Extensive use & $\begin{array}{l}\text { high added value products- dragon's } \\
\text { blood }\end{array}$ \\
\hline
\end{tabular}

indicating a positive market preview.

Some enterprises have already found the commer-cial opportunities for $C$. nudiflora and have invested in planting and production, such as Luohuazizhu suppository, which have the indications as anti-inflammatory (Ying and Guocai, 2006), for detoxification, convergence, hemostasis bacterial infection caused by inflammation, acute infectious hepatitis, and respiratory and gastrointestinal bleeding (Jie et al., 2010).

\section{N. officinalis (Danmu)}

The $N$. officinalis is a kind of common drug used by $\mathrm{Li}$ people as anti-inflammatory drug. The modern research found that the main effects of $N$. officinalis included not only anti-inflammation, but also heat-clearing, detoxicating, and analgesia (Liang et al., 2011). It is used to treat acute tonsillitis, acute pharyngitis, acute conjunctivitis, and upper respiratory tract infection (Yan and Yanli, 2012), and has demonstrated extraordinary efficacy on diabetes mellitus (Gidado, 2004).

The growth period of $N$. officinalis is 5 to 6 years.

It has strong adaptability, good resistance, and great growth ability after cutting. It grows easily and has no serious pest problems (Zhiyuan et al., 2010). The planting of $N$. officinalis in Hainan has been formed to a certain scale. The $N$. officinalis has been planted on Wuzhishan up to 1000 acres and the investment has been more than 10 million RMB since 2003.

The present productions include Danmu injections, Danmu extract tablets, and Danmu extract capsules. In daily consumption, it can be made into Danmu wine. The $N$. officinalis is one of the representative species of large-scale production in $\mathrm{Li}$ ethnomedicine. It has good medicinal value and is edible.

\section{A. oxyphylla (Yizhi)}

A. oxyphylla mostly grows on Hainan Island because of the warm and humid environment. Its flowering period is about 2 to 5 months, and the maturing period is 6 months. The medicinal part is its fruit. Wildlife resources have decreased since the 1950s, and the present products are cultivated versions. A. oxyphylla is very good for the cardiovascular system (Shoji et al., 1984) and gastrointestinal system (Yamahara et al., 1990; Kubo et al., 1995) and has a significant effect on the treatment of allergies (Kim et al., 2002) and cancer (Chun et al., 2002). The Li people made the fruit into powder to treat stomach pain (Mingsheng, 2008). One clinical study found that A. oxyphylla is effective in the treatment of diarrhea (Sakai et al., 1986), enuresis, hyperactivity, and insomnia (Hengliang et al., 2002).

Meanwhile, modern research has found that it contains a high amount of taurine (Junping et al., 2002), the "smart factor", and one of the essential nutrients for the body, especially for infants' growth and educational nourishment as well as for delaying aging among the elderly (Huiling, 2006). Its isolated compounds can be used as therapeutic agents for sexual dysfunction and 
amnesia (Kubo et al., 1995). Therefore, A. oxyphylla has a strong potential as a health food.

Due to its short growth cycle and more and increased attention from the government, more farmers are planting A. oxyphylla.

\section{D. angustifolia}

$D$. angustifolia is distributed only along the coastal areas of Hainan Island. It has been shown to be 8,000 years to 10,000 years old. It grows slowly and is one of the national protected species. Its resin, which is known as "Dragon's blood" is used as medicine in many places and promotes a variety of pharmacological activities, including anti-inflammatory (Yuli et al., 2010), anti-fungal (Yodosuka et al., 2000), anti-arrhythmic (Nambu et al., 1989), anti-thrombotic (Nian et al., 2010), hemostatic (Dongxu, 2001), and wound healing (Ping et al., 2000; Dongxu, 2001). In recent years, compounds with antitumor activity (Wenli et al., 2005) have been isolated from it; these have shown an inhibition effect on the growth of nasopharyngeal carcinoma cells (Reddy et al., 1984), liver cells, and leukemia (Yodosuka et al., 2000). The Li people use the resin to treat throat pain (Mingsheng, 2008).

\section{PROBLEMS}

Based on the literature review, some problems have been identified with $\mathrm{Li}$ ethnomedicine. First of all, the planting of Li medicinal material is still based on scattered plantings by farmers (Wang Yeqiao, 2006), making it difficult for standardized production and large-scale industrialization due to the lack of an effective quality standard system and monitoring (Yali et al., 2009). And the sustainable use of $\mathrm{Li}$ medicinal resources has become another outstanding problem. Due to the lack of collection, collation, purification, and rejuvenation of the herbal resources, some species have been overharvested and leading to destruction of their ecological environment. Many wild medicinal resources with special effects, such as periwinkle, gall wood, and the leader of maple have been rapidly depleted or have altogether disappeared. The manufacturers that use these herbs as raw materials, such as the Periwinkle medicine, cannot produce them at full capacity.

Secondly, the $\mathrm{Li}$ nation has no writing system. The heritage of $\mathrm{Li}$ drugs relies on an oral tradition between teacher and student. This way of sharing knowledge has resulted in the loss of many drugs and prescriptions. Moreover, the knowledge of $\mathrm{Li}$ ethnomedicine is fragmented. It has no systematic theory or drug standards. The existing national and local policies conflict with the practice of physicians using $\mathrm{Li}$ ethnomedicine, whose practice qualification is not recognized by the government. This situation is not conducive to the heritage and development of Li ethnomedicine.

\section{SUGGESTIONS}

First of all, the comprehensive utilization of $\mathrm{Li}$ ethnomedicine resources needs to be strengthened. The utilization includes two aspects. The first is the comprehensive evaluation and exploration of resources in the development process, making full use of medicinal plants in a variety of ways. Studies have confirmed that the root and leaf of Bryophyllum pinnatum (L.f.) Oken can stop bleeding, cure swelling and pain (Surong et al., 2004); the fruit and leaf of Amomum longiligulare T.L.Wu contain some common active ingredients. These examples underscore the need for the comprehensive utilization of different parts of herbal medicine. The second is the transfer of useless or low efficacy ingredients in the waste into a chemical composition with medicinal value through synthesis or structural modification. The extent and level of comprehensive utilization of medicinal plants reflect the degree of scientific research and standards. China attaches great importance to comprehensive utilization of herbal and drug production dregs, such as alkaloids extracted from Cephalotaxus which in recent years has shown good effects on the treatment of leukemia (Yumei et al., 1995); taxol extracted from the yex, which is a strong inhibitor of tumor cells (Slichenmyer and Von Hoff, 1991); and insulin analogue from the seeds of some cucurbits (Shouyan, 1992), which is helpful for the treatment of diabetes (Zheng et al., 1996; Toshihiro et al., 2009).

And then, we should strengthen the promotion of new technologies and new methods. The development and utilization of $\mathrm{Li}$ ethnomedicine need new technologies and the application of new methods. The bio-pharmaceuticals developed rapidly thanks to high-tech tools during the past 10 years, especially genetic engineering, which has become an important technology for pharmaceutical products replacement. In the future, cell engineering, genetic engineering, and fermentation engineering will greatly promote the development and utilization of Li ethnomedicine.

In addition, the research into $\mathrm{Li}$ traditional medicine needs to be strengthened. The collation of $\mathrm{Li}$ medicine theory and clinical experience needs to be increased. The relevant departments, including the government of Hainan province, the Administration of Traditional Chinese Medicine of Hainan, and the Ministry of Health, should pay more attention to resource surveys and research to rescuing the $\mathrm{Li}$ culture as soon as possible. Specific conservation and research institutions need to be established in order to conduct further research and enhance the role of $\mathrm{Li}$ drugs. The protection of the ecological environment in the process of developing of the Li drugs needs to be also considered.

\section{ACKNOWLEDGEMENTS}

This study was supported by the Macau Science and 


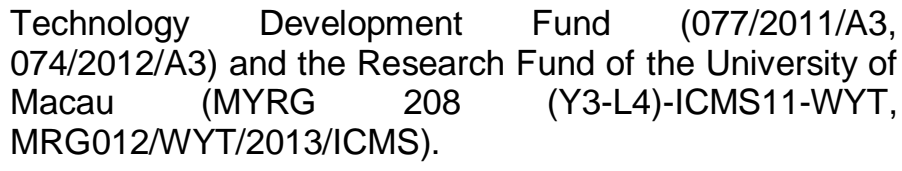

\section{REFERENCES}

Bin X, Li L, Shangda C (1995). The Cytological Mechanism of The Chinese Medicinal Herb Callicapa Nudiflora. Academic J. Guangdong College Pharm. 11: 141.

Bingchun G, Rongtao L, Xinquan Y, Daolin D (2007). Ethnobotany Studies on Medicinal Plants Used by Li Nationality in Wuzhishan Area of Hainan Province. Chin. J. Ethnomed. Ethnopharm. 4:32-34.

Caicheng Z (2007). Overview of development status of Li drugs. J. Med. Pharm. Chin. Minorities. 5(5):2-4.

Changyu B, Chaojun F, Zhanjuan C, Heping B (2012). Study on the Chemical Constituents from the stems of Melicope ptelefolia(Champ.ex Benth.)Hartley in Hainan. J. Hainan Normal Univ. (Natural Science). 01:66-70

Chun KS, Park KK, Lee J, Kang M, Surh YJ (2002). Inhibition of mouse skin tumor promotion by anti-inflammatory diarylheptanoids derived from Alpinia oxyphylla Miquel (Zingiberaceae). Oncol. Res. 13: 37-45.

Dehuan L, Wenqiang Z, Zhenzhen X, Weicong G, Binghui L (2002). Clinical Study on JIANNAO Mixture for Senile Vascular Dementia. J. Fujian College Tradit. Chin. Med. 12:40-42.

Dongxu W (2001). Advances in studies on resin of Dracaena cochinchinensis. Chin. Tradit. Herb. Drugs 32(11):1053-1054.

Gidado A, Ameh DA, Atawodi SE (2004). Effect of Nauclea latifolia leaves aqueous extracts on blood glucose levels of normal and alloxan-induced diabetic rats. Afr. J. Biotechnol. 4:91-93.

Haifeng L, Weisheng Z, Ying $Y$ (2012). Therapeutic Effect of Percutaneous Transhepatic Artery Embolism with Fructus Bruceae Oil Emulsion and Oral Use of Chinese Medicine for Late Liver Cancer. J. Guangzhou Univ. Tradit. Chin. Med. 05:527-531

Haofu D, Wenli M (2008). Records of Li Folk Medicine. China Science and Technology Press, Beijing.

Hengliang Z, Liping Z, Li C (2002). An Experimental Study on Sedative and Hypnotic Effects of Yizhiren Oral Liquid. J. Guiyang Med. College 2:132-135.

Hongmei A, Bing H, Jiulin C, Zhihua Y, Miao J, Chao G, Sanli X (2012). Effects of Dihuang Yizhifang on apoptosis related gene expression in senile dementia rats induced by A 1-40. Pharmacol. Clin. Chin. Mater. Med. 28:18-20.

Huiling D (2006). Studies of Several Traditional Chinese Medicine Extracts on Anti-aging in Mice. Dalian University of Technology, Dalian.

Jian F, Shaoyi K, Xiang-zhou Z, Gui-lan X (2002). Studies on Antiinflammatory Effect of Danmu Extract Tablets. Nat. Sci. J. Hainan Univ. 20:54.

Jie Z, Baoquan L, Feng F, Yuping T, Wenyuan L (2010). Chemical constituents from Callicarpa nudiflora and their hemostatic acitivity. Chin. J. Chin. Mater. Med. 35:45-47.

Jinping C, Lin D, Weiwei G (2012). Research progress of Callicarpa nudiflora. Drugs Clin. 27:52-54.

Junping Z, Boli Z, Yongyan W, Xiaoyu C, Ling L (2002). Effects of Qing Nao Yi Zhi Fang on Human Fetal Cerebral Neuronal Cells in Primary Culture with Oxygen Deprivation Condition. Chin. J. Basic Med. Tradit. Chin. Med. 8:17-20.

Junqing Z, Shuiping D, Weili Y, Jianping T, Mingsheng L (2009). Analysis of $\mathrm{Li}$ medicinal plant resources in Hainan province. $\mathrm{J}$. Hainan Med.I College 15:201-205.

Kim SH, Choi YK, Jeong HJ, Kang HU, Moon G, Shin TY, Kim HM (2002). Suppression of immunoglobulin E-mediated anaphylactic reaction by Alpinia oxyphylla in rats. Imunopharmacol. Immunotoxicol. 22:267-270.

Kubo M, Matsuda H, Suo T, Yamanaka J, Sakanaka M, Yoshimura M (1995). Study on Alpiniae Fructus. I. Pharmacological evidence of efficacy of Alpiniae Fructus on ancient herbal literature. Yakugaku Zasshi. 115:852-856.
Liang C, Na L, Yaqiong J, Gang D, Zhenzhong W, Wei X (2011). Antiinflammatory and Analgesic Effects of Extracts from the Leaves of Nauclea officinalis. Chin. J. Exp. Tradit. Med. Formulae 17:25-27.

Long M, Qiu D, Li F, Johnson F, Luft B (2005). Flavonoid of Drynaria fortunei protects against acute renal failure. Phytother. Res. 19(5):422-427.

Mingsheng L (2008). Li pharmacy Introduction. People's Health Publishing House, Beijing.

Nambu T, Huang X, Shu Y, Huang S, Hattori M, Kakiuchi N, Wang Q, Xu GJ (1989). Chronotnpic effect of the methanolic extracts of the Plants of the Paris species and steroidal glycosides isolated from P.

vietnamensis pn spontaneous beating of myocarolial cells. Planta Med. 55(6):501.

Nian X, Yujuan L, Yulin D (2010). Experimental Study on Antithrombotic Effect of Dragon's Blood Extracts, Proceedings of 2010 China Pharmaceutical Conference and the Tenth Chinese pharmacists weeks.

Ping W, Qingyun D (2000). Advances in the constituents and clinical research of the resin of the Dragon's Blood. Strait Pharm. 12:1-2.

Reddy KS, Shekhani MS, Berry DE, Lynn DG, Hecht SM (1984). Afromontoside a new cytotoxic principle from Dracaena of romontane. J. Chem. Soc. Perkin Trans. Org. Chem. 5:987.

Sakai K, Oshima N, Kutsuna T, Miyazaki Y, Nakajima H, Muraoka T, Okuma K, Nishino T (1986). Pharmaceutical studies on crude drugs. I. Effect of the Zingiberaceae crude drug extracts on sulfaguanidine absorption from rat small intestine. Yakugaku Zasshi. 106:947-951.

Shoji N, Umeyama A, Asakawa Y, Takemoto T, Nomoto K, Ohizum Y (1984). Structural determination of nootkatol, a new sesquiterpene isolated from Alpinia oxyphylla Miquel possessing calciumantagonistic activity. J. Pharm. Sci. 73:843.

Shouyan Z (1992). The Exact of Insulin analogue from Momordica charantia Linn. Chin. Pharm. 5:46-49.

Shui G (2006). Studies on Protective Effect of Protocatechuic Acid from Alpinia oxyphylla in PC12 Cells, Dalian University of Technology. Dalian University of Technology, Dalian.

Slichenmyer WJ, Von Hoff DD (1991). Taxol: a new and effective anticancer drug. Anti-cancer Drugs 2(6):519-530.

Surong C, Suhua G, Yeqing Z (2004). Pharmaceutical Research Progress of Bryophyllum pinnatum. Fujian J. Tradit. Chin. Med. 35:51.

Toshihiro M, Takanori K, Satoshi T, Mai N, Haruka N, Eriko I, Torao I (2009). Effect of Momordica charantia on Adenosine Monophosphate-activated Pro-tein Kinase in Genetically Type 2 Diabetic Mice Muscle. J. Health Sci. 55(5):805-808.

Wang Yeqiao YB (2006). Protection and Exploitation of the Medicinal Plant Resources in Hainan. Chin. Wild Plant Resourc. 25:40-43.

Wenli M, Haofu D, Jiao W, Ling Z, Kui H (2005). Study on the New Use of Antitumor of Dracaena cambodiana. J. Chin. Med. Mater. 28:871 874.

Wenjing W, Jun W, Gaoxiong R (2011). Study on the anti-inflammatory and analgesic effects of two kinds of Sambucus chinensis extracts. West Chin. J. Pharm. Sci. 3:247-249

Xianhui Y, Shangwen C, Shiming D (2009). Study on the Chemical Constituents of Croton crassifolius. Lishizhen Med. Mater. Medica Res. 3:515-518.

Xiaobai C, Yaokun G, Xiaoping W, Shihua Z, Jianling L, Ping M (2010). Effects of Abrus mollis on Blood Lipids and Liver Lipids in Hyperlipoidemia Rats. Chin. Pharm. 03:202-205

Xinghua $L$ (2009). Studies on the Anti-diarrhea Effect of Seed Alpiniae oxyphyllae and the Influence of Stir-heating with Salt Solution on It, Chengdu University of Traditional Chinese Medicine. Chengdu University of Traditional Chinese Medicine, Chengdu.

Xingqi T, Haisheng C, Congli X, Runhui L, Weidong X (2003). Studies on Chemical Constituents in the Ervatamia hainanensis. Chin. J. Chin. Mater. Med. 11:1040-1042.

Yali G, Qin P, Minren H (2009). Ethnobotany and exploitation of medicinal plant resource in Hainan. J. Nanjing Forestry Univ. 33:18 20.

Yamahara J,YingHua L, Tamai Y (1990). Anti-ulcer effect in rats of bitter cardamon constituents. Chem. Pharm. Bull. 38:3053-3056.

Yan J, Yanli L (2012). Quality Analysis Study of Fathead Tree and Three Different Fomulations. Chin. Pharm. Affairs 26:34-36. 
Ying C, Guocai Y (2006). Study on the Anti-inflammatory and Immunologic Effects of Callicarpa nudiflora Hook. Et Am. Guangdong Trace Elements Sci. 8:39-42.

Ying C, Guocai Y (2007). The Callicarpa nudiflora on hemorheology. Chin. Remedies Clin. 4:293-294.

Yingbo S, Jingzhao W, Dingji L (1994). Dictionary of Li nation. Zhongshan University Press, Guangdong.

Yodosuka A, Mimaki Y, Sashida Y (2000). Steroidal saponins from Dracaenasurculosa. J. Nat. Prod. 63:1237-1243.

Yuli C (2010). The Research on Analgesic Mechanism of Dragon's Blood and Its Components - Loureirin B, Central South University for Nationalities.

Yumei Y, Chengxiong X, Runhua S, Jiyu G, Guangjian C (1995). Studies on the Anticancer Effect of HH07A, a Derivative of Hainanensine. Acta Pharm. Sinica 1:12-16.
Zheng P, Baoyuan L, Wangyi L, Shanwen J (1996). Characterization of the Enzymatic Mechanism of 7-Momorcharin, a Novel Ribosome Inactivating Protein with Lower Molecular Weight of 11,500 Purified from the Seeds of Bitter Gourd (Momordica charantia). Biochem. Biophy. Res. Commun. 1(229):287-294.

Zhiyuan Z, Qiumei L, Qian L, Xiu-feng L (2010). Introduction of Nauclea officinalis cultivation techniques. J. Shanxi College Tradit. Chin. Med. 11:69-72. 